\title{
Optimal Energy Scheduling Strategy in Power System using Bat Algorithm Optimization Approach
}

\author{
X. W. $\mathrm{Ng}^{1}$, N. F. Ramli ${ }^{2}$, N. A. M. Kamari ${ }^{3}$, M. A. Zulkifley ${ }^{4}$, I. Musirin ${ }^{5}$ \\ ${ }^{1,2,3,4}$ Electrical, Electronic and System Engineering Department, Faculty of Engineering and Built Environment, \\ UniversitiKebangsaan Malaysia, Malaysia, azwank@ukm.edu.my \\ ${ }^{5}$ Faculty of Electrical Engineering, UniversitiTeknologi Mara, Malaysia, ismailbm@ salam.uitm.edu.my
}

\begin{abstract}
This paper presents an energy scheduling strategy for power system using Bat Algorithm (BA) optimization technique. BA is inspired by the natural behaviour of microbats, that of echolocation. The paper focuses on the minimization of the total power and cost needed according to the power demand and limits of power generation. Two systems, the IEEE 9 bus with 3 generator system and IEEE 30 bus with 6 generator system, are studied and simulated using Matlab. The performance of BA is compared with evolutionary programming (EP) technique. The simulation results indicate that BA performs better than EP in determining the optimal power generation valuewith minimum generation cost.
\end{abstract}

Key words :Energy Scheduling; Bat Algorithm; Evolutionary Programming

\section{INTRODUCTION}

The development of a country depends strongly on the efficiency of its power system. Cost handling to avoid unnecessary expenses is very important in maintaining the efficiency of the power system and economy of the country. Economic dispatch (ED) is an important key to consider in the development of the power system. It has been widely used in power system designs to minimize the cost while achieving the power demand [1-5].

ED means lesser energy will be wasted and lower costs will be incurred to achieve the requirements. Various methods have been used, including optimization method. Optimization method can be categorized into several categories, including metaheuristic [6-8], combinatorial optimization [9-11] and linear programming [12-14]. A power system can be built up by more than one generator depending on the power demand. The cost of power generated and distributed from different generators vary. Therefore, the use of optimization methods is very important in ensuring the success of economic delivery.

The mathematical equations involved in economic dispatch depend on the objective functions of the research. Economic dispatch is widely used in the power system, which may be economic load dispatch or economic emission dispatch, which controls potentially harmful gas emissions. The power loss of transmission can also be taken into the account of without affecting the final achievement of the power generated according to power demand.

Optimization approaches are frequently chosen to tune variables of devices in solving power system stability problems. Some new algorithms, such as Particle Swarm Optimization [15-17], Gravitational SearchAlgorithm [18-20], Firefly [21-23], Whale Optimization Algorithm [24-26], Ant Colony Optimization [27-29], Flower Pollination Algorithm [30-32], Moth Flame Optimization [33-35] and Bat Algorithm [36-38] have also gained attention because of their efficiency. These algorithms are inspired from nature with the characteristic of the investigated biological system. These methods are swarm-intelligence based, making them easier to implement and obtain better outcomes. Some other algorithms were inspired by the biological system, such as the Genetic Algorithm [39-41], Artificial Immune System [42-44] and Evolutionary Programming [45-47]are commonly used.

In this paper, two types of ED simulation using nature-inspired Bat Algorithm and bio-inspired Evolutionary Programming are conducted according to the IEEE standards of nine bus with three generator and thirty bus with six generator systems. The results are analyzed in the aspect of cost minimization according to power generated based on load demand.

The rest of the paper is organized as follows: Section 2 presents the basic calculation of ED. Section 3 and Section 4 explain the formulation for Bat Algorithm and Evolutionary Programming optimization techniques, respectively. Section 5 provides the simulation results and discussions. Lastly, Section 6 presents the conclusions.

\section{ECONOMIC DISPATCH}

The objective of economic load dispatch problem is to minimize the cost of total power generated with optimum generation values allocation while satisfying equality and 
equality constraint. The mathematical equation that represents the objective function is similar to the quadratic equation as below [1]:

$$
F_{t}=\sum_{i=1}^{n} F_{i}\left(P_{i}\right)=\sum_{i=1}^{n}\left(a_{i} P_{i}^{2}+b_{i} P_{i}+c_{i}\right)
$$

where $F_{t}$ is the total cost for all generators, $n$ is the number of generators, $a_{i}, b_{i}, c_{i}$ are coefficients of the $i$ th generator and $P_{i}$ is the power generated by the ithgenerator. The total power generated of the system is shown in Equation (2):

$$
\sum_{i=1}^{n} P_{i}=P_{d}+P_{l}
$$

Here, $P_{d}$ is the power demand at the load side and $P_{l}$ is the power loss during transmission process. Generator load is in the range as follows:

$$
P_{i}^{\min } \leq P_{i} \leq P_{i}^{\max }
$$

where $P_{i}^{\min }$ and $P_{i}^{\max }$ are the minimum and maximum generation limit of the $i$ thgenerator, respectively.

\section{BAT ALGORITHM}

Bat Algorithm (BA) has gained popularity because of its efficiency in optimization problem, which is inspired by the natural behaviour of microbats, that of echolocation. The movement of bats at night depends on the radiation of short pulses they emit. The increase in pulse emission rates and increase in frequency shorten the wavelength of echolocation, which help micro bats detect the object more accurately. The echolocation or sonar that bounces back from the objects is known as a signal of the surrounding situation. With this natural behaviour, bats can find their way even without any light. The special characteristic of bats being able to differentiate whether it is food, prey or barriers in their way is much more suitable to use in the complicated analysis including ED.

Several rules for BA were considered to start the optimization [36]:

a) All bats use their instinct of echolocation to define the distance and location $x$.

b) A random flying bat at $x$ with velocity $v_{i}$ has a fixed frequency varied between $f_{\text {min }} \sim f_{\text {maks }}$ searches for food. Here, $f_{\min }$ and $f_{\text {maks }}$ are minimum and maximum frequency, respectively. The frequencyf, pulse rate $r$ and loudness $A$ are varied from time to time.

c) The loudness is assumed to be varied between $A_{o} \sim A_{\min }$. Here, $A_{o}$ is a large value, while $A_{\min }$ is a minimum value.

For the implementation in ED, several equations are represented in BA. BA optimization process starts with producing initial value of location $x$, frequency $f$, velocity $v$, loudness $A$, pulse rate $r$, and fitness $K$ for $j$ of bats.Equation 4 represents frequency of bat which will be updated from time to time for a better solution. The $f_{\text {maks }}$ and $f_{\min }$ are set at 2 and 0 , respectively in this paper.

$$
f_{j}=f_{\text {min }}+\left(f_{\text {maks }}-f_{\text {min }}\right) \beta
$$

Here, $f_{j}$ is the frequency of the $j$ th bat, $\beta$ is a uniformly distributed random vector in the range of $[0,1]$. The calculation of velocity vand locationxare shown in Equation (5) and (6), respectively.

$$
v_{j}^{t}=v_{j}^{t-1}+\left(x_{j}^{t-1}-x_{b}\right) f_{j}
$$

$x_{j}^{t}=x_{j}^{t-1}+v_{j}^{t}$

Here, $x_{j}^{t}$ and $v_{j}^{t}$ are the position and velocity components of the $j$ th bat in the population at the $t$ th iteration. $x_{b}$ is the current best locationof the last iteration.

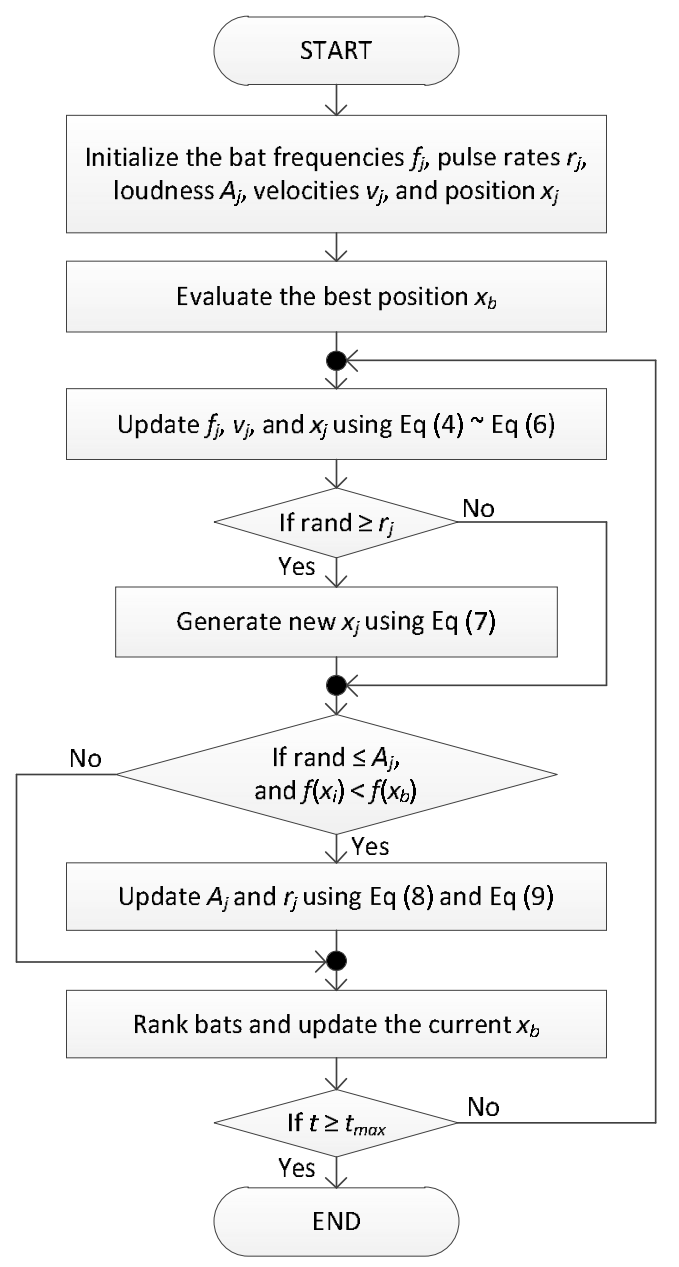

Figure 1: Process Flow of the BA

In addition to global search, BA also has local search capabilities. Adaptive parameters are used to achieve a balance between these two search capabilities. During the local search, Equation (7) is used to select the current best solution. 
$x_{j}^{t}=x_{b}+\epsilon A^{t}$

Here, $\varepsilon$ is the random number that lies between $[0,1] \cdot A^{t}$ is the average value of loudness for all bats at the th iteration.

Both value of loudness $A$ and pulse rate $r$ changes with increase in number of iterations. The value of $A$ will decreases and $r$ will increases, as bat increases towards its prey. Equations (8) and (9) represent the pulse rate rand loudness Aof the BA.

$$
\begin{aligned}
& r_{j}^{t}=r_{j}^{t-1}\left[1-e^{(-\gamma t)}\right] \\
& A_{j}^{t}=\alpha A_{j}^{t-1}
\end{aligned}
$$

Here, $r_{j}^{t}$ and $A_{j}^{t}$ are the pulse rate and loudness components of the $j$ th bat in the population at the $t$ th iteration. $\gamma$ and $\alpha$ are constant numbers fixed at 0.1 and 0.97 , respectively.

After the search for the best location, the best fitness with the optimum cost of generation will be obtained. The iteration counter will be set to $t=t+1$ and algorithm will start again. The process will stop when the iteration achieved the maximum number of iterations, $t_{\max }$. Figure 1 shows the process flow of the BA.

\section{EVOLUTIONARY PROGRAMMING}

Evolutionary Programming (EP) is one of the stochastic optimization strategies that minimise or maximise the objective function when random variables exist. This method is based on the concept of mutation between parents and their offspring. The use of the mutation operator creates a population for global search. It starts with a population of the randomly generated solution and undergoes generations or iterations until the best solution is found. Implementation of EP for optimization problem involves three stages, namely, initialization, mutation, and competition and selection [47].

Same asthe BA technique, the optimization process of EP starts with producing initial value of parent $y_{l}$ and fitness $K_{l}$. lis number of populations. Mutation creates a mutated population or offspring, $y_{l+m}$ from each parent population $y_{l}$ :

$$
\begin{gathered}
\sigma_{l}=\frac{K_{l}}{K_{\max }} *\left(y_{l}^{\text {maks }}-y_{l}^{\min }\right) \\
y_{l+m}=y_{l}+\sigma_{l} * N(0,1)
\end{gathered}
$$

Here, $m$ is total number of parents. $N(0,1)$ is Gaussian random variable with mean and standard deviation are 0 and 1 , respectively. $K_{\max }$ is the maximum fitness of the last iteration. Based on the mutated population, fitness $K$ for each offspring population is computed.

Competition and selection are the final stage to finalize the best solution of each iteration. Both group of parents and offspring are combined. The first $l$ individuals (or top half of parents-offspring combination) with higher fitness $K$ are selected as populations of the next generation. The iteration counter will be set to $t=t+1$ and algorithm will start again. The process will stop when the iteration achieved $t_{\max }$. Figure 2 shows the process flow of the EP.

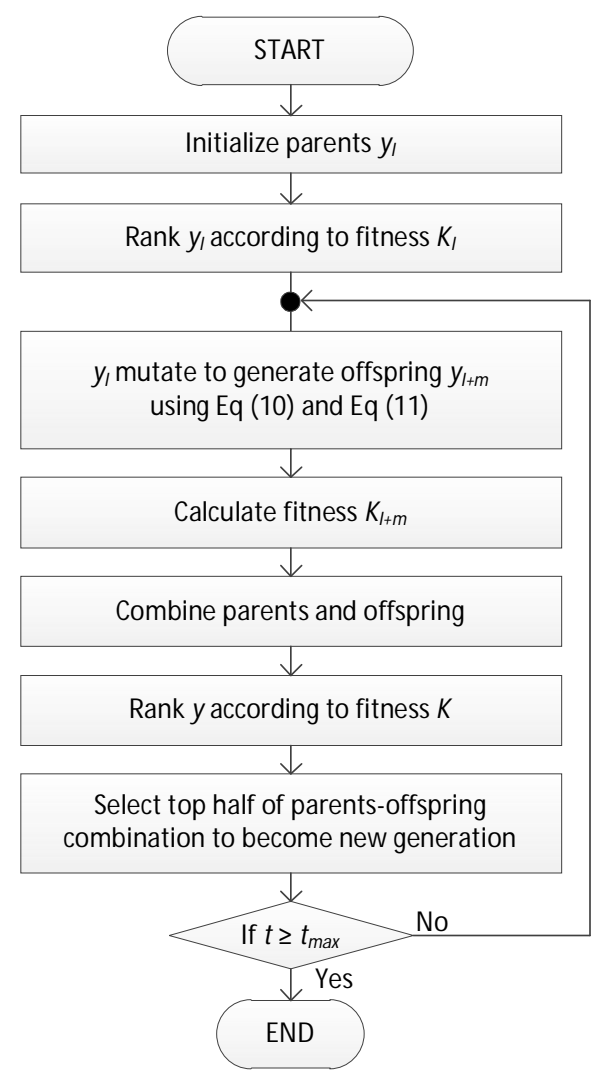

Figure 2: Process Flow of the EP

\section{RESULTS AND ANALYSIS}

In this paper, the performance of BA and $\mathrm{EP}$ are conducted according to two types of systems: IEEE standards of nine bus with three generator system (System 1 ) and thirty bus with six generator system (System 2) [5].

\subsection{Nine Bus with Three Generator System (System 1)}

The load demand for IEEE nine bus with three generator system (System 1) is set at $150 \mathrm{MW}$. The power generation limits for the generating units in System 1 are shown in Table 1. Table 2 shows the coefficients for the quadratic cost function for the generating units for System 1.

Table 1: Power limit for the generator inSystem 1

\begin{tabular}{ccc}
\hline Generator & Minimum (MW) & Maximum (MW) \\
\hline$P_{1}$ & 10 & 85 \\
$P_{2}$ & 10 & 80 \\
$P_{3}$ & 10 & 70 \\
\hline
\end{tabular}

Table 3 shows the total power generated using EP and BA. Both methods show good results and fulfilled the load 
demand. Although both techniques produce power as required, $\mathrm{BA}$ is able to provide the same amount of power as the load demand, while a power surplus of $0.6 \mathrm{MW}$ is generated using the EP approach.

Table 2: Coefficients of the quadratic cost function for System 1

\begin{tabular}{cccc}
\hline Generator & $\boldsymbol{a}_{\boldsymbol{i}}\left(\mathbf{M W}^{2}\right)$ & $\boldsymbol{b}_{\boldsymbol{i}}(\mathbf{M W})$ & $\boldsymbol{c}_{\boldsymbol{i}}$ \\
\hline$P_{1}$ & 0.008 & 7.0 & 200 \\
$P_{2}$ & 0.009 & 6.3 & 180 \\
$P_{3}$ & 0.007 & 6.8 & 140 \\
\hline
\end{tabular}

Table 3: Power generated by System 1

\begin{tabular}{crr}
\hline Generator & EP $(\mathbf{M W})$ & BA $(\mathbf{M W})$ \\
\hline$P_{I}$ & 23.7900 & 10.1000 \\
$P_{2}$ & 78.5300 & 79.9700 \\
$P_{3}$ & 48.3500 & 59.9300 \\
\hline Total Generated & $\mathbf{1 5 0 . 6 0 0 0}$ & $\mathbf{1 5 0 . 0 0 0 0}$ \\
\hline
\end{tabular}

Table 4 shows the total cost of power generated. The EP significantly optimized the higher cost of power generation as compared to the BA. The cost needed for BA is RM1502.05 and RM1510.06 for EP. This shows that BA method produced cheaper generation cost compared to EP in System 1 for the load demand of $150 \mathrm{MW}$.

Table 4: Generation cost for System 1

\begin{tabular}{crr}
\hline Generator & $\mathbf{E P}(\mathbf{R M} / \mathbf{h})$ & $\mathbf{B A}(\mathbf{R M} / \mathbf{h})$ \\
\hline$P_{1}$ & 366.53 & 270.70 \\
$P_{2}$ & 674.75 & 683.82 \\
$P_{3}$ & 468.78 & 547.53 \\
\hline Total Cost & $\mathbf{1 5 1 0 . 0 6}$ & $\mathbf{1 5 0 2 . 0 5}$ \\
\hline
\end{tabular}

\subsection{Thirty Bus with Six Generator System (System 2)}

The load demand for IEEE thirty bus with six generator system (System 2) is set at 700MW. Table 5 shows the power generation limit for the units in System 2. Table 6 shows the coefficients of quadratic cost functions for the generating units for System 2.

Table 5: Power limit for the generator in System 2

\begin{tabular}{ccc}
\hline Generator & Minimum (MW) & Maximum $(\mathbf{M W})$ \\
\hline$P_{1}$ & 10 & 125 \\
$P_{2}$ & 10 & 150 \\
$P_{3}$ & 35 & 225 \\
$P_{4}$ & 35 & 210 \\
$P_{5}$ & 130 & 325 \\
$P_{6}$ & 125 & 315 \\
\hline
\end{tabular}

Table 6: Coefficients of the quadratic cost function for System 2

\begin{tabular}{cccc}
\hline Generator & $\boldsymbol{a}_{\boldsymbol{i}}\left(\mathbf{M W}^{\mathbf{2}}\right)$ & $\boldsymbol{b}_{\boldsymbol{i}}(\mathbf{M W})$ & $\boldsymbol{c}_{\boldsymbol{i}}$ \\
\hline$P_{1}$ & 0.15247 & 38.53973 & 756.79886 \\
$P_{2}$ & 0.10587 & 46.15916 & 451.32513 \\
$P_{3}$ & 0.02803 & 40.39650 & 1049.9977 \\
$P_{4}$ & 0.03546 & 38.30553 & 1243.5311 \\
$P_{5}$ & 0.02111 & 36.32782 & 1658.5690 \\
$P_{6}$ & 0.01799 & 38.27041 & 1356.6592 \\
\hline
\end{tabular}

Table 7 shows the total power generated using EP and BA. Both methods show good results and fulfilled the load demand. But the results show significantly that BA method is generated $700 \mathrm{MW}$, the same amount of power as the load demand, while a power surplus of $3.41 \mathrm{MW}$ is generated using the EP.

Table 7: Power generated by System 2

\begin{tabular}{crr}
\hline Generator & EP $(\mathbf{M W})$ & BA $(\mathbf{M W})$ \\
\hline$P_{l}$ & 58.0781 & 20.2100 \\
$P_{2}$ & 27.2488 & 13.6470 \\
$P_{3}$ & 76.0794 & 89.9420 \\
$P_{4}$ & 65.2168 & 86.7600 \\
$P_{5}$ & 217.4980 & 325.0037 \\
$P_{6}$ & 259.2867 & 164.4373 \\
\hline Total Generated & $\mathbf{7 0 3 . 4 0 7 8}$ & $\mathbf{7 0 0 . 0 0 0 0}$ \\
\hline
\end{tabular}

Table 8 shows the total cost of power generated. The cost required for BA and EP are RM32983.16 and RM33410.67, respectively. From the result in System 2, it indicates that the BA performs better than EP because it can save up to RM427.51 of the generation cost as compared to EP in System 2 for the load demand of $700 \mathrm{MW}$.

Table 8: Generation cost for System 2

\begin{tabular}{crr}
\hline Generator & EP $(\mathbf{R M} / \mathbf{h})$ & $\mathbf{B A}(\mathbf{R M} / \mathbf{h})$ \\
\hline$P_{1}$ & 2996.46 & 1536.15 \\
$P_{2}$ & 1709.41 & 1081.41 \\
$P_{3}$ & 4123.39 & 4683.41 \\
$P_{4}$ & 3741.77 & 4567.02 \\
$P_{5}$ & 9559.89 & 13465.38 \\
$P_{6}$ & 11279.75 & 7649.79 \\
\hline Total Cost & $\mathbf{3 3 4 1 0 . 6 7}$ & $\mathbf{3 2 9 8 3 . 1 6}$ \\
\hline
\end{tabular}

\section{CONCLUSION}

$\mathrm{EP}$ and BA fulfil the requirements for solving the economic load dispatch problem. The comparison among the efficiency of economic load dispatch is performed considering the generation cost. Higher efficiency in economic load dispatch indicates lower generation cost. BA exhibited better results compared to EP with the least excess power generated and cost savings. These show that BA is a more efficient method for solving economic load dispatch problems in power systems.

\section{ACKNOWLEDGEMENT}

This work was supported by Ministry of Education Malaysia (FRGS/1/2018/TK04/UKM/02/7).

\section{REFERENCES}

1. M. Basu. Fast convergence evolutionary programming for economic dispatch problems, IET Generation, Transmission and Distribution, Vol. 11, No. 16, pp. 4009-4017, November 2017. 
2. A. Sundaram. Combined heat and power economic emission dispatch using hybrid NSGA II-MOPSO algorithm incorporating an effective constraint handling mechanism, IEEE Access, Vol. 8, pp. 13748-13768, January 2020.

3. N. Roslan, P. S. A. Khader, A. Nordin, and S. Jaafar. A hybrid optimization technique for solving economic emission load dispatch problem, International Journal of Emerging Trends in Engineering Research, Vol. 8, No. 1.1, pp. 113-119, September 2020.

4. M. A. Hannan, M. G. M. Abdolrasol, M. Faisal, P. J. Ker, R. A. Begum, and A. Hussain. Binary particle swarm optimization for scheduling MG integrated virtual power plant toward energy saving, IEEE Access, Vol. 7, pp. 107937-107951, August 2019.

5. N. A. M. Kamari, N. A. Rahmat, and I. Musirin. Optimal power scheduling strategy in power systems using swarm optimization technique, International Journal of Advanced Trends in Computer Science and Engineering, Vol. 8, No. 1.6, pp. 246-251, December 2019.

6. M. Ellahi, and G. Abbas. A hybrid metaheuristic approach for the solution of renewables-incorporated economic dispatch problems, IEEE Access, Vol. 8, pp. 127608-127621, July 2020.

7. E. Mostafa, M. Abdel-Nasser, and K. Mahmoud. Performance evaluation of metaheuristic optimization methods with mutation operators for combined economic and emission dispatch, in Nineteenth International Middle East Power Systems Conference, Cairo, Egypt, 2017, pp. 1004-1009.

8. M. I. Alomoush. Optimal combined heat and power economic dispatch using stochastic fractal search algorithm, Journal of Modern Power Systems and Clean Energy, Vol. 8, No. 2, pp. 276-286, March 2020.

9. K. I. Min, S. W. Lee, and Y. H. Moon. Economic dispatch algorithm as combinatorial optimization problems, International Journal of Control, Automation and Systems, Vol. 6, No. 4, pp. 468-476, August 2008.

10. D. Gupta, and S. K. Jain. Solving combinatorial Optimization problem of economic load dispatch using modified hopfield neural network, inJoint International Conference on Power System Technology and IEEE Power India Conference, New Delhi, India, 2008, pp. 1-6.

11. A. Hoese. Economic dispatch and energy pricing: a combinatorial approach, in 5th Latin-American Congress In Electricity Generation And Transmission, Sao Pedro, Brazil, 2003, pp. 1-8.

12. Z. Wu, J. Ding, Q. H. Wu, Z. Jing, and J. Zheng. Reserve constrained dynamic economic dispatch with valve-point effect: a two-stage mixed integer linear programming approach, CSEE Journal of Power and Energy Systems, Vol. 3, No. 2, pp. 203-211, June 2017.

13. W. Wei, D. Wu, Z. Wang, S. Mei, and J. P. S. Catalao. Impact of energy storage on economic dispatch of distribution systems: a multi-parametric linear programming approach and its implications, IEEE Open Access Journal of Power and Energy, Vol. 7, pp. 243-253, July 2020.
14. R. A. Jabr, A. H. Coonick, and B. J. Cory. A homogeneous linear programming algorithm for the security constrained economic dispatch problem, IEEE Transactions on Power Systems, Vol. 15, No. 3, pp. 930-936, August 2000.

15. Q. Zhao, and C. Li. Two-stage multi-swarm particle swarm optimizer for unconstrained and constrained global optimization, IEEE Access, Vol. 8, pp. 124905-124927, July 2020.

16. M. Sato, Y. Fukuyama, T. Iizaka, and T. Matsui. Total optimization of energy networks in a smart city by multi-swarm differential evolutionary particle swarm optimization, IEEE Transactions on Sustainable Energy, Vol. 10, No. 4, pp. 2186-2200, November 2018.

17. N. A. M. Kamari, I. Musirin, A. N. Dagang, and M. H. M. Zaman. PSO-based oscillatory stability assessment by using the torque coefficients for smib, Energies, Vol. 13, No. 5, pp. 1231, January 2020.

18. Anumeha, K. Paul, K. B. Yadav, and N. Kumar. Application of gravitational search algorithm to analyze economic load dispatch in power system network, in IEEE 7th Power India International Conference, Bikaner, India, 2017, pp. 1-6.

19. M. S. H. Lipu, M. A. Hannan, A. Hussain, M. H. Saad, A. Ayob, and M. N. Uddin. Extreme learning machine model for state-of-charge estimation of lithium-ion battery using gravitational search algorithm, IEEE Transactions on Industry Applications, Vol. 55, pp. 4225-4234, August 2019.

20. M. K. M. Zamani, I. Musirin, M. S. Omar, S. I. Suliman, N. A. M. Ghani, and N. A. M. Kamari. Gravitational search algorithm based technique for voltage stability improvement, Indonesian Journal of Electrical Engineering and Computer Science, Vol. 9, No. 1, pp. 123-130, January 2018.

21. S. R. Spea. Economic-emission dispatch problem using firefly algorithm, in Nineteenth International Middle East Power Systems Conference, Cairo, Egypt, 2017, pp. 671-676.

22. M.H. Hussain, I. Musirin, S.R.A. Rahim, and A.F. Abidin. Modified firefly algorithm-artificial neural network based technique for the prediction of time-current characteristic in directional overcurrent relay, International Journal of Emerging Trends in Engineering Research, Vol. 8, No. 1.1, pp. 170-178, September 2020.

23. L. A. Wong, H. Shareef, A. Mohamed, and A. A. Ibrahim. An enhanced opposition-based firefly algorithm for solving complex optimization problems, JurnalKejuruteraan, Vol. 26, pp. 89-96, December 2014.

24. P. K. M. Reddy, and M. Prakash. Optimal dispatch of energy resources in an isolated micro-grid with battery energy storage system, in 4th International Conference on Intelligent Computing and Control Systems, Madurai, India, 2020, pp. 730-735.

25. R. Vijay, J. S. Dhillon, and P. Mathuria. Economic emission load dispatch using fuzzy decision based whale algorithm, in 8th International Conference on Power Systems, Jaipur, India, 2019, pp. 1-6. 
26. N. A. M. Kamari, I. Musirin, Z. A. Hamid, and A. A. Ibrahim. Optimal tuning of SVC-PI controller using whale optimization algorithm for angle stability improvement, Indonesian Journal of Electrical Engineering and Computer Science, Vol. 12, No. 2, pp. 612-619, November 2018.

27. N. A. Rahmat, N. F. A. Aziz, M. H. Mansor, and I. Musirin. Optimizing economic load dispatch with renewable energy sources via differential evolution immunized ant colony optimization technique, International Journal on Advanced Science Engineering and Information Technology, Vol. 7, No. 6, pp. 2012-2017, September 2017.

28. J. Zhou, C. Wang, Y. Li, P. Wang, C. Li, P. Lu, and L. Mo. A multi-objective multi-population ant colony optimization for economic emission dispatch considering power system security, Applied Mathematical Modelling, Vol. 45, pp. 684-704, May 2017.

29. Z. A. Hamid, I. Musirin, M. N. A. Rahim, and N. A. M. Kamari. Application of electricity tracing theory and hybrid ant colony algorithm for ranking bus priority in power system, International Journal of Electrical Power \& Energy Systems, Vol. 43, No. 1, pp. 1427-1434, December 2012.

30. K. Dhayalini, and A. S. Siva. Flower pollination algorithm for economic dispatch problems with non-smooth cost function, in 2nd International Conference on Power and Embedded Drive Control, Chennai, India, 2019, pp. 254-257.

31. Sarjiya, P. H. Putra, and T. A. Saputra. Modified flower pollination algorithm for nonsmooth and multiple fuel options economic dispatch, in 8th International Conference on Information Technology and Electrical Engineering, Yogyakarta, Indonesia, 2016, pp. 1-5.

32. N. F. Ramli, N. A. M. Kamari, S. A. Halim, and I. Musirin. Solving non-smooth economic load dispatch problem via flower pollination algorithm, International Journal of Emerging Trends in Engineering Research, Vol. 8, No. 1.1, pp. 158-165, September 2020.

33. I. N. Trivedi, A. Kumar, A. H. Ranpariya, and P. Jangir. Economic load dispatch problem with ramp rate limits and prohibited operating zones solve using levy flight moth-flame optimizer, in International Conference on Energy Efficient Technologies for Sustainability, Nagercoil, India, 2016, pp. 442-447.

34. A. A. Elsakaan, R. A. E. Sehiemy, S. S. Kaddah, and M. I. Elsaid. An enhanced moth-flame optimizer for solving non-smooth economic dispatch problems with emissions, Energy, Vol. 157, pp. 1063-1078, August 2018.

35. N. F. Ramli, N. A. M. Kamari, M. A. Zulkifley, and I. Musirin. Optimal power scheduling for economic dispatch using moth flame optimizer, Indonesian Journal of Electrical Engineering and Computer Science, Vol. 20, No. 1, pp. 379-384, October 2020.

36. E. S. Ali. 2014. Optimization of power system stabilizers using bat search algorithm, International Journal of Electrical Power and Energy Systems, Vol. 61, pp. 683-690, October 2014.
37. H. Liang, Y. Liu, F. Li, and Y. Shen. A multiobjective hybrid bat algorithm for combined economic/emission dispatch, International Journal of Electrical Power and Energy Systems, Vol. 101, pp. 103-115, October 2018.

38. N. N. Islam, M. A. Hannan, H. Shareef, and A. Mohamed.Power system stabilizer design using BAT optimization algorithm in multimachine power system, in IEEE Student Conference on Research and Developement, Putrajaya, Malaysia, 2013, pp. 540-544.

39. J. K. Pattanaik, M. Basu, and D. P. Dash. Improved real coded genetic algorithm for dynamic economic dispatch, Journal of Electrical Systems and Information Technology, Vol. 5, No. 3, pp. 349-362, December 2018.

40. Y. Asnawi, and T. Hasannuddin. Voltage constrained optimal power flow based using genetic algorithm, JurnalKejuruteraan, Vol. 27, pp. 9-14, April 2015.

41. A. H. A. H. Ayoppan, M. F. Ibrahim, and M. H. M. Zaman. A genetic algorithm with online learning approach for improving loop closure detection of a visual SLAM, International Journal of Advanced Trends in Computer Science and Engineering, Vol. 8, No. 1.6, pp. 159-166, December 2019.

42. A. Y. Hatata, G. Osman, and M. M. Aladl. An optimization method for sizing a solar/wind/battery hybrid power system based on the artificial immune system, Sustainable Energy Technologies and Assessments, Vol. 27, pp., Pages 83-93, June 2018.

43. X. Kong, D. Liu, J. Xiao, and C. Wang. A multi-agent optimal bidding strategy in microgrids based on artificial immune system, Energy, Vol. 189, pp. 116154, December 2019.

44. N. A. M. Kamari, I. Musirin, Z. A. Hamid, and M. N. A. Rahim. Computational intelligence approach for SVC-PID controller in angle stability improvement, in IEEE International Power Engineering and Optimization Conference,Melaka, Malaysia, 2012, pp. 442-447.

45. S. A. Syed Mustaffa, I. Musirin, M. K. M. Zamani, and M. M. Othman. Pareto optimal approach in Multi-Objective Chaotic Mutation Immune Evolutionary Programming (MOCMIEP) for optimal Distributed Generation Photovoltaic (DGPV) integration in power system, Ain Shams Engineering Journal, Vol. 10, No. 4, pp. 745-754, December 2019.

46. J. Sun, J. Deng, and Y. Li. Indicator \& crowding distance-based evolutionary algorithm for combined heat and power economic emission dispatch, Applied Soft Computing, Vol. 90, pp. 106158, May 2020.

47. N. A. M. Kamari, I. Musirin, and M. M. Othman. Application of evolutionary programming in the assessment of dynamic stability, in International Power Engineering and Optimization Conference,Selangor, Malaysia, 2010, pp. 43-48. 